\title{
Realized Volatility Transmission: The Role of Jumps and Leverage Effects
}

\author{
Michael Souček ${ }^{\mathrm{a}}$, Neda Todorova ${ }^{\mathrm{b}}$ \\ ${ }^{a}$ Department of Business Administration \\ European University Viadrina \\ Große Scharrnstraße 59, 15230 Frankfurt (Oder), Germany \\ Email: soucek@europa-uni.de \\ ${ }^{b}$ Corresponding author \\ Griffith Business School, Griffith University \\ 170 Kessels Road, Nathan, Queensland 4111, Australia \\ Email: n.todorova@griffith.edu.au \\ Phone: +6173735 7219, Fax: +6173735 3719
}

\begin{abstract}
This paper is the first to employ a multivariate extension of the LHAR-CJ model for realized volatility of Corsi and Renó (2012) considering continuous and jump volatility components and leverage effects. The model is applied to financial (S\&P 500), commodity (WTI crude oil) and forex (US\$/EUR) intraday futures data and allows new insights in the transmission mechanisms among these markets. Besides significant leverage effects, we find that the jump components of all considered assets do not contain incremental information for the one-step ahead realized volatility. The volatility of S\&P 500 and US\$/EUR exchange rate futures exhibits significant spillovers to the realized volatility of WTI. Moreover, decreasing equity prices appear to increase volatility in other markets, while strengthening of the US\$ seems to calm down the crude oil market.
\end{abstract}

Keywords: Volatility transmission; Jumps; Leverage Effects; Realized Volatility. JEL Classification: C5, G1, G15.

\section{Introduction}

The increasing integration of major financial markets has generated strong interest in understanding the nature of volatility spillover effects from one market to another. The amount of research in this field has skyrocketed with the development of the Generalized Autoregressive Conditional Heteroscedasticity (GARCH) model framework and its multivariate extensions. However, the various MGARCH specifications employed in the literature utilize mostly returns sampled at daily or lower frequencies, which are known to provide noisy volatility estimates. This is the first study employing a multivariate extension of the LHAR-CJ model of Corsi and Renó (2012) which decomposes realized volatility (an intraday data based metric) into continuous and jump components and takes leverage effects into account. These extenstions have not been addressed by the few other studies utilizing a multivariate version of this model (Bauer and Vorkink, 2011; Bubák et al., 2011; Soucek and Todorova, 2013) even though they have proven very useful 
for enhancing the forecasting power in its univariate form (Andersen et al., 2007; Corsi and Renó, 2012). The introduced framework is applied to uncover volatility transmission between S\&P 500, Western Texas Intermediate crude oil (WTI) and US\$/EUR exchange rate futures.

Furthermore, to our knowledge, this study is the first employing the univariate version of the LHAR-CJ model to crude oil data. It also shows that the jump components are insignificant for explaining future daily realized volatility for all considered assets. The univariate estimation results also uncover different autocorrelation patterns in the time series of realized volatility of the analyzed assets showing that equity futures tend to react strongly to short-term shocks while the driving force of daily oil and exchange rate volatility seems to emerge from their weekly and monthly realized volatility components.

While the provided evidence that the jump volatility components are insignificant for equity and forex data is conform with current literature, the multivariate model reveals new insights into the transmission patterns of leverage effects across various markets. First, negative returns in the equity futures market have positive impact on the volatility in both other markets and negative crude oil returns affect positively the volatility in the forex futures market. Second, the model uncovers the interesting fact that a strengthening of the dollar (i.e. a decreasing US\$/EUR exchange rate) tends to calm down the WTI futures volatility. This result is possibly related to the fact that WTI is the most important crude oil benchmark for the US economy. Positive news related to the US economy are usually followed by an appreciation of the dollar. Via this link, a strong US economy implying a strong dollar might have a soothing effect on the crude oil volatility.

\section{Data and methodology}

Our analysis is based on 5-minute returns (in US\$) of the one-month futures contracts on Light Sweet Crude Oil (WTI), the S\&P 500 (e-mini futures, in the following referred to as S\&P 500) and the US\$/EUR exchange rate. The data are obtained from the Thomson Reuters Tick History database of the Securities Industries Research Centre of Asia Pacific (SIRCA) and cover the period from January 2004 to September 2012. The futures contracts are traded at the CME 24 hours a day during the whole sample period.

\subsection{The econometrics of jumps}

To define the considered realized volatility components, we build on the commonly used continuous time jump diffusion process,

$$
d p_{t}=\mu_{t} d t+\sigma_{t} d W_{t}+\kappa_{t} d q_{t} \quad 0 \leq t \leq T
$$

where $\mu_{t}$ is a continuous and locally bounded variation process, $\sigma_{t}$ is a strictly positive stochastic volatility process, and $W_{t}$ is a standard Brownian motion. The counting process $q_{t}$ is normalized such that $d q_{t}=1$ corresponds to a jump at time $\mathrm{t}$ and $d q_{t}=0$ otherwise. $\kappa_{t}$ is the random jump size at time $t$ if $d q_{t}=1$. The quadratic variation for the cumulative 
return process is then

$$
[r, r]_{t}=\int_{0}^{t} \sigma_{s}^{2} d s+\sum_{0<s \leq t} \kappa_{s}^{2}
$$

where the second component of the right-hand side of (2) consists of the sum of squared jumps observed between 0 and $t$. After establishing realized volatility of day $t$ as the sum of compounded intra-day returns,

$$
R V_{t}=\sum_{j=1}^{M} r_{t, j}^{2}, \quad t=1, \ldots T
$$

the non-parametric approach of Barndorff-Nielsen and Shephard (2004, 2006) is used to separate the continuous path and jump components in equation (2), considering bipower and tripower variation measures. The bipower-variation is defined as

$$
B V_{t}=\mu_{1}^{-2} \frac{M}{M-1} \sum_{j=2}^{M}\left|r_{t, j}\right|\left|r_{t, j-1}\right|, \quad t=1, \ldots T
$$

where $\mu_{1}=\sqrt{2 / \pi}$ and the realized tripower quadricity is

$$
T Q_{t}=\mu_{4 / 3}^{-3} \frac{M^{2}}{M-2} \sum_{j=3}^{M}\left|r_{t, j}\right|^{4 / 3}\left|r_{t, j-1}\right|^{4 / 3}\left|r_{t, j-2}\right|^{4 / 3}, \quad t=1, \ldots T,
$$

where $\mu_{4 / 3}=2^{2 / 3} \Gamma(7 / 6) / \Gamma(1 / 2)$. $M$ denotes the number of intraday returns.

Using equation (3) and the definition of quadratic variation, Barndorff-Nielsen and Shephard (2004) show that $B V_{t}$ is a consistent estimator of integrated volatility,

$$
B V_{t} \rightarrow_{p} \int_{t-1}^{t} \sigma^{2}(s) d S \quad \text { for } M \rightarrow \infty
$$

Therefore, the difference $\left(R V_{t}-B V_{t}\right)$ converges to the sum of squared jumps that have occurred during the period. Since the jumps may be non-zero in finite samples due to sampling variation, even if there are no real jumps (Busch et al., 2011), a definition of a significant jump component is needed. We apply the test statistic proposed by Huang and Tauchen (2005),

$$
Z_{t}=\sqrt{M} \frac{\left(R V_{t}-B V_{t}\right) R V_{t}^{-1}}{\left(\left(\mu_{1}^{-4}+2 \mu_{1}^{-2}-5\right) \max \left\{1, T Q_{t}, B V_{t}^{-2}\right\}\right)^{1 / 2}} .
$$

If there are no jumps, the test statistic $Z_{t}$ converges to standard normal distribution, as $M$ approaches infinity, while large positive values indicate jumps occurring within the period. The significant jump component of realized volatility is

$$
J_{t}=I_{Z_{t}>\Phi_{1-\alpha}}\left(R V_{t}-B V_{t}\right), \quad t=1, \ldots T
$$

where $I_{R}$ is the indicator of event $R$ and $\Phi_{1-\alpha}$ is the $100(1-\alpha) \%$ point in the standard 
normal distribution at the significance level $\alpha$. For $I_{Z_{t}>\Phi_{1-\alpha}}=1, J_{t}$ is considered as excess realized volatility above the bipower variation, and thus attributable to jumps in the price process. The continuous component of quadratic variation is estimated by the remainder of $R V_{t}$

$$
C_{t}=R V_{t}-J_{t}, \quad t=1, \ldots T
$$

If there is no significant jump, $C_{t}$ equals $R V_{t}$. The consistency of the estimators of both components of quadratic variation, i.e.,

$$
C_{t} \rightarrow_{p} \int_{t-1}^{t} \sigma^{2}(s) d S \quad \text { and } \quad J_{t} \rightarrow_{p} \sum_{j=q(t-1)+1}^{q(t)} \kappa^{2}\left(t_{j}\right),
$$

may be achieved by letting $\alpha \rightarrow 0$ and $M \rightarrow \infty$ simultaneously. As a result, this approach allows a nonparametric consistent estimation of both components of quadratic variation. In our analysis we employ conform with the literature (e.g. Andersen et al., 2007) a confidence level of $99.9 \%$.

\subsection{Multivariate LHAR-CJ model}

As already mentioned, the various MGARCH specifications employed by most of the studies utilize returns sampled at a daily or lower frequency, but using these returns results in much noisier volatility estimates than realized volatility. A simple autoregressive-type model for realized volatility which considers volatilities observed over different time periods is proposed by Corsi (2009). The heterogeneous autoregressive model (HAR) is based upon the idea that traders with different time horizons can cause different types of volatility and it is motivated by the heterogeneous market hypothesis presented by Müller et al. (1997). It is empirically supported by the observation that volatility over longer time intervals has a stronger influence on volatility over shorter time intervals than vice versa. The most common HAR model specification considers volatility as a linear function of the average daily $(d)$, weekly $(w)$, and monthly $(m)$ realized volatilities (Corsi, 2009).

We formulate the multivariate model following Andersen et al. (2007), who, among others, consider the continuous and jump decomposition of realized volatility separately within a univariate version of the HAR-CJ model. We extend the model by leverage effects as, proposed by Corsi and Renó (2012),

$$
r_{t-h, t}=\frac{1}{h} \sum_{j=1}^{h} \min \left(0, r_{t-j}\right)
$$

so that the obtained univariate model LHAR-CJ model can be written as follows:

$$
\begin{aligned}
R V_{t, t+h} & =\beta_{0}+\beta_{C d} C_{t}+\beta_{C w} C_{t-4, t}+\beta_{C m} C_{t-21, t} \\
& +\beta_{J d} J_{t}+\beta_{J w} J_{t-4, t}+\beta_{J m} J_{t-21, t}+\beta_{R} r_{t-h, t}+\epsilon_{t+h} .
\end{aligned}
$$


In this study, we introduce and estimate the multivariate extension of the above model. Generally, an empirical application of the multivariate extension for $N$ assets requires $7 N^{2}+N$ coefficient estimates. In order to decrease the number of estimated coefficients, we run a preliminary analysis showing that the weekly and monthly jump components do no increase the explanatory power of the model as well as its forecasting ability, and hence are omitted. ${ }^{1}$ Furthermore, we focus on the one-step ahead realized volatility $(h=1)$, so that, the applied multivariate LHAR-CJ model takes the form,

$$
R V_{t+1}=\beta_{0}+A_{d} C_{t}+A_{w} C_{t-4, t}+A_{m} C_{t-21, t}+B J_{t}+R r_{t}+\epsilon_{t+1}
$$

where $\boldsymbol{A}_{\boldsymbol{d}}, \boldsymbol{A}_{\boldsymbol{w}}, \boldsymbol{A}_{\boldsymbol{m}}, \boldsymbol{B}$ and $\boldsymbol{R}$ are coefficient matrices. The vectors $\boldsymbol{C}_{\boldsymbol{t}-\boldsymbol{k}, \boldsymbol{t}}, k=4,21$ represent the vectors of the standardized volatility sums over the last 5 and 22 days, respectively, and the vectors $\boldsymbol{J}_{\boldsymbol{t}}$ and $\boldsymbol{r}_{\boldsymbol{t}}$ contain the significant jump components and the leverage effect proxy for day $t$. Conform with extant literature, we use logarithmic realized variance. Since the jumps $J_{t}$ are often equal to zero, following with Andersen et al. (2007), the transformation $\ln \left(1+J_{t}\right)$ is employed.

\section{Empirical results}

\subsection{Univaraite HAR models}

We run different specifications of the HAR models for realized volatility showing that weekly and monthly jump components are generally not significant in the regression equation for daily realized volatility and do not increase the explanatory power of the model (Table 1). The forecasting error measured by minimum absolute forecasting error (MAFE) and root mean squared error (RMSE) is also the lowest for the specification without monthly and weekly jump components. For all three assets, we find adjusted $R^{2}$ over $50 \%$. The decomposition of realized volatility into continuous and jump components as well as the consideration of leverage effects increase the $R^{2}$ and lower the forecasting error measures.

Based on these results, in order to decrease the number of estimated coefficients in the multivariate model, we discard the weekly and monthly jumps. The empirical evidence presented in the following is based on the transmission model (13).

\subsection{Causality tests}

Estimating the multivariate model in (13), we first test for causality using the log likelihood ratio test (LR-test). Results are presented in table 2. According to the null hypothesis of the test, incorporation of the asset's (continuous, jump and leverage) components in the row does not increase the explanatory power of the equation for the realized volatility of the asset the column. We reject the null for the S\&P 500 and forex relationship and find them to exhibit bivariate causality, and WTI volatility to be a follower of

\footnotetext{
${ }^{1}$ These results are presented in the next section.
} 
the equity index and forex volatility. Furthermore, the significance of the impact of equity futures volatility on WTI appears to be stronger than that emerging from the forex market.

Our finding that the dynamics of crude oil realized volatility is following the volatility changes in the equity and forex markets is at odds with existent studies suggesting the existence of spillovers mainly from oil to equity markets or of bidirectional interrelationships between the two markets (e.g. Malik and Hammoudeh, 2007; Aloui et al., 2008; Malik and Ewing, 2009). In contrast, Thuraisamy et al. (2013) and Soucek and Todorova (2013) present similar evidence for the leading role of equity markets in the equity-oil market relationship indicating that the major part of the significance of this relationship might be related to the turbulent market downturn starting 2007/2008. In this period, the overall market uncertainty and the following recession was rather sourced in the financial market and spilled over to the crude oil markets via its link to the economy. Our results support this evidence.

Table 2: Multivariate causality tests

\begin{tabular}{lccc}
\hline & S\&P 500 & WTI & Forex \\
\hline S\&P 500 & - & 35.81 & 33.38 \\
& & $(0.00)$ & $(0.00)$ \\
WTI & 4.99 & & 6.79 \\
& $(0.42)$ & - & $(0.23)$ \\
Forex & 24.44 & 9.81 & - \\
& $(0.00)$ & $(0.08)$ & \\
\hline
\end{tabular}

The table shows the results for LR-test based on the FIML estimated model in (13). It tests whether the variables in the first column cause the variables in the rows. The $p$-values in brackets are based on the $\chi^{2}$ distribution.

\subsection{Regression results}

The estimation results for the transmission model (13) are reported in table 3. We observe different autocorrelation structures of the realized volatility for the three assets measured by the magnitude of the estimated coefficients of the lagged realized volatility components. In the case of S\&P 500, the impact of the own short-term volatility on the one-step ahead volatility is stronger, while for WTI and forex, the weekly and monthly volatility seem to contain most of the relevant information for future daily realized volatility.

Focusing on the source of the spillover effects, it becomes obvious that the shortterm volatility of the equity futures does have a positive impact on the volatility in the other two markets. Furthermore, we observe a significant spillover effect emerging from the weekly continuous volatility component of WTI to S\&P 500, and from the daily and weekly volatility components of forex futures to the equity market. Additionally, the forex futures seem to react to the dynamics of the short- and long-term volatility components of the WTI futures. Last, consistent with the literature considering HAR-CJ models (e.g. 
Andersen et al., 2007, Bauer and Vorkink, 2011), none of the jump components in the model is significant at the $10 \%$ level.

Due to its sophisticated specification which discerns spillover effects emerging from volatilities realized over different time horizons, the multivariate LHAR-CJ model is capable of uncovering unique results related to the leverage effects and their spillover to other markets. First, we document a significant leverage effect for all considered markets. Second, there is significant transmission of leverage effects of the equity to the crude oil and forex market; i.e., decreasing equity prices are followed by rising volatility in other markets. Surprisingly, an increase in the US\$/EUR exchange rate is followed by a decrease in the realized volatility of the crude oil futures. A decrease in the forex rate signals strengthening of the US\$, which may calm down the WTI market. 
Table 3: Estimation results from the multivariate LHAR-CJ transmission model

\begin{tabular}{|c|c|c|c|}
\hline & S\&P 500 & WTI & Forex \\
\hline Int. & $\begin{array}{c}-0.3276^{* * *} \\
(0.099)\end{array}$ & $\begin{array}{c}-0.3334^{* * *} \\
(0.104)\end{array}$ & $\begin{array}{c}-0.4154^{* * *} \\
(0.075)\end{array}$ \\
\hline$\beta_{C d}^{S P}$ & $\begin{array}{c}0.4246^{* * *} \\
(0.021)\end{array}$ & $\begin{array}{c}0.1026^{* * *} \\
(0.029)\end{array}$ & $\begin{array}{c}0.04601^{* *} \\
(0.020)\end{array}$ \\
\hline$\beta_{C w}^{S P}$ & $\begin{array}{c}0.3189^{* * *} \\
(0.035)\end{array}$ & - & - \\
\hline$\beta_{C m}^{S P}$ & $\begin{array}{c}0.1278^{* * *} \\
(0.034)\end{array}$ & - & - \\
\hline$\beta_{J d}^{S P}$ & - & - & - \\
\hline$\beta_{R}^{S P}$ & $\begin{array}{c}-17.0633^{* * *} \\
(1.515)\end{array}$ & $\begin{array}{c}-4.6635^{* * *} \\
(1.741)\end{array}$ & $\begin{array}{c}-5.4022^{* * *} \\
\quad(1.256)\end{array}$ \\
\hline$\beta_{C d}^{W T I}$ & & $\begin{array}{c}0.1350^{* * *} \\
(0.20)\end{array}$ & $\begin{array}{c}0.0447^{* * *} \\
(0.015)\end{array}$ \\
\hline$\beta_{C w}^{W T I}$ & - & $\begin{array}{c}0.3891^{* * *} \\
(0.044)\end{array}$ & - \\
\hline$\beta_{C m}^{W T I}$ & $\begin{array}{c}0.0862^{*} \\
(0.051)\end{array}$ & $\begin{array}{c}0.3211^{* * *} \\
(0.048)\end{array}$ & - \\
\hline$\beta_{J d}^{W T I}$ & - & - & - \\
\hline$\beta_{R}^{W T I}$ & & $\begin{array}{c}-6.8011^{* * *} \\
(0.888)\end{array}$ & - \\
\hline$\beta_{C d}^{F}$ & $\begin{array}{c}-0.1588^{* * *} \\
(0.031)\end{array}$ & - & $\begin{array}{c}0.1175^{* * *} \\
(0.022)\end{array}$ \\
\hline$\beta_{C w}^{F}$ & $\begin{array}{c}0.1374^{* *} \\
(0.067)\end{array}$ & - & $\begin{array}{c}0.4603^{* * *} \\
(0.046)\end{array}$ \\
\hline$\beta_{C m}^{F}$ & - & - & $\begin{array}{c}0.3446^{* * *} \\
(0.046)\end{array}$ \\
\hline$\beta_{J d}^{F}$ & - & - & - \\
\hline$\beta_{R}^{F}$ & & $\begin{array}{c}6.2496^{* *} \\
(2.971)\end{array}$ & $\begin{array}{c}-6.7419^{* * *} \\
(2.268)\end{array}$ \\
\hline$D$ & $\begin{array}{c}-1.6975^{* * *} \\
(0.177)\end{array}$ & $\begin{array}{c}-0.5631^{* * *} \\
(0.108)\end{array}$ & $\begin{array}{c}-1.4274^{* * *} \\
(0.126)\end{array}$ \\
\hline$R^{2}$ & 0.777 & 0.598 & 0.700 \\
\hline MAFE & 0.3759 & 0.3379 & 0.2772 \\
\hline RMSE & 0.4981 & 0.5250 & 0.3660 \\
\hline
\end{tabular}

The table summarizes the FIML estimation results for the model (13) for different volatility components on the left-hand side. The table displays only estimates significant at $10 \%$ level. ${ }^{* * *}\left({ }^{* *},{ }^{*}\right)$ marks coefficients significant at the $1 \%(5 \%$, $10 \%$ ) level, MAFE and RMSE stand for mean absolute forecasting error and root mean squared error, respectively. $D$ is dummy variable taking into account days when there was a trading day in other markets, but the analyzed market was closed. 
Considering the explanatory power and the forecasting ability of the multivariate model, the estimates reveal further interesting results. First, we observe a substantial increase in the adjusted $R^{2}$, which is almost $5 \%$ in the case of WTI; including volatility information from other markets obviously contributes to the explanation of volatility changes in the observed market (Table 1 and 3). Furthermore, for all three assets the multivariate specification leads to lower mean absolute forecasting error (MAFE) and mean root squared error (MRSE) for one-step ahead realized volatility forecasts than the corresponding univariate models. This is a noteworthy result especially against the backdrop of the increased number of coefficients used to create the forecasts. Both results understate the hypothesis of cross market volatility transmission effects having a significant contribution to explaining the realized volatility of the analyzed assets.

\section{Conclusion}

This is the first study of a multivariate version of the HAR model accounting for continuous and jump realized volatility components as well as leverage effects. Applying the model to equity, forex and crude oil market intraday data, we document several interesting insights in the prevailing volatility spillover mechanisms. First, the jump components of the realized volatility of S\&P 500, WTI and US\$/EUR futures are found neither to possess explanatory power for the own one-step ahead realized volatility nor to exhibit spillover effects to other markets. In the case of equity futures, the highest parameter estimate is assigned to the own short-term volatility component, while in the case of crude oil and forex weekly and monthly components seem to contain the majority of the information. Causality analysis indicates that the equity market and forex volatility lead the volatility of crude oil, which can be attributed to the financial uncertainty emerging from the financial markets over the last decade. We also document a significant transmission of leverage effects from the equity to the crude oil and forex market with a decrease in equity futures prices positively affecting the volatility in other markets under consideration. Furthermore, an appreciation of the dollar appears to induce lower volatility in the WTI crude oil market. Overall, the multivariate LHAR-CJ model allows for new insights in the nature of the volatility spillovers and should be considered when aiming at an in-depth analysis of transmission mechanisms.

\section{Acknowledgments}

We would like to thank Andrew Harvey and Philipp Andres, and to gratefully acknowledge Griffith Business School's valuable trading room facilities for sourcing data for this research.

\section{References}

Aloui, C., Jammazi, R., Dhakhlaoui, I., 2008. Crude oil volatility shocks and stock market returns. J. Energ. Market 1, 69-96. 
Andersen, T. G., Bollerslev, T., Diebold, F.X., 2007. Roughing it up: Including jump components in the measurement, modeling and forecasting of return volatility. Rev. Econ. Stat. 89, 701-720.

Bauer, G. H., Vorkink, K., 2011. Forecasting multivariate realized stock market volatility. J. Econometrics 160, 93-101.

Barndorff-Nielsen, O.E., Shephard, N., 2004. Power and bipower variation with stochastic volatility and jumps. J. Fin. Econometrics 2, 1-57.

Barndorff-Nielsen, O.E., Shephard, N., 2004. Econometrics of testing for jumps in financial economics using bipower variation. J. Fin. Econometrics 4, 1-30.

Bubák, V., Kočenda, E., \& Žikeš, F., 2011. Volatility transmission in emerging European foreign exchange markets. J. Bank. Finance 35, 2829-2841.

Busch, T., Christensen, B.J., Nielsen, M.O., 2011. The role of implied volatility in forecasting future realized volatility and jumps in foreign exchange, stock, and bond markets. J. Econometrics 160, 48-57.

Corsi F., Renó R., 2012. Discrete-time volatility forecasting with persistent leverage effect and the link with continuous-time volatility modeling. J. Bus. Econ. Stat. 30, 368-380.

Corsi, F., 2009. A simple approximate long-memory model of realized volatility. J. Fin. Econometrics 7, 174-196.

Huang, X., Tauchen, G., 2005. The relative contribution of jumps to total price variance. J. Fin. Econometrics 3, 456-499.

Malik, F., Ewing, B., 2009. Volatility transmission between oil prices and equity sector returns. International Rev. Fin. Anal. 18, 95-100.

Malik, F., Hammoudeh, S., 2007. Shock and volatility transmission in the oil, US and Gulf equity markets. Int. Rev. Econ. Finance 16, 357-368.

Müller, U., Dacorogna, M., Dav, R., Olsen, R., Pictet, O., Weizsacker, J.v., 1997. Intraday trading volume and return volatility of the DJIA stocks: A note. J. Bank. Finance 27, 2035-2043.

Souček, M., Todorova, N., 2013. Realized volatility transmission between crude oil and equity futures markets: A multivariate HAR approach. Energ. Econ. 40, 586-597.

Thuraisamy, K., Sharma, S., Ali Ahmed H., 2013. The relationship between Asian equity and commodity futures markets. J. Asian Econ. (in press). 